\title{
More Attention Should Be Paid to Monitoring of Abdominal Obesity among Children and Adolescents
}

\author{
Ying-xiu Zhang Jin-shan Zhao Zun-hua Chu \\ Shandong Center for Disease Control and Prevention, Shandong University Institute of Preventive \\ Medicine, Jinan, China
}

\section{Dear Editor,}

During the past decades, childhood obesity has increased dramatically both in developing and developed countries $[1,2]$. In $2009-2010,18.2 \%$ of US children and adolescents aged $6-19$ years ( $19.8 \%$ of boys and $16.5 \%$ of girls) were found to be obese [3]. In 2013 , it was found that $23.8 \%$ of boys and $22.6 \%$ of girls in developed countries, and $12.9 \%$ of boys and $13.4 \%$ of girls in developing countries were overweight or obese [4]. Since childhood obesity is associated with many health risks and also because it progresses into adulthood, the widespread prevalence of obesity in children and adolescents has become an important public health concern challenging the world today $[5,6]$.

Body mass index (BMI) is perhaps the most commonly used measure for defining general obesity (GOB) in clinical practice and while conducting population surveys. However, BMI cannot distinguish between fat and fat-free mass; it provides no information on body fat distribution. Also, elevated BMI need not necessarily reflect increased adiposity. Individuals with excessive muscle growth can show a large BMI without having an unhealthy level of fat, and may be misjudged to be obese; health risks of such people would be overestimated if screening is done by BMI alone. Waist circumference (WC), on the other hand, provides relevant information about fat distribution and reflects the degree of abdominal adiposity. Evidence reveals that WC provides information beyond $\mathrm{BMI}$ in the assessment of obesity-related health risks in clinical settings [7]. It has been recognized that individuals with a similar BMI can vary considerably in their abdominal fat mass; a few individuals may exhibit a 'normal' BMI but may have a disproportionately large WC. In other words, children and adolescents in the normal BMI category may suffer from abdominal obesity (AOB) and their health risks could be missed out on oversight if screening is done only by BMI.

Several studies have examined the secular trend in measuring WC and BMI among children and adolescents; they have consistently showed that WC is being increasingly accepted as a standard measure than BMI [8-10]. Based on 2 cross-sectional surveys of students aged 7-18 years, carried out in 2010 and 2014 in Shandong Province $(n=72,755)$, we examined the recent trends in BMI and WC. An increasing trend in
BMI and WC was observed in both boys and girls between 2010 and $2014(\mathrm{p}<0.01)$, BMI Z-scores increased by 0.11 (boys) and 0.13 (girls) units, and WC Z-scores increased by 0.22 (boys) and 0.28 (girls) units; WC has increased more than BMI (fig. 1). Similarly, the prevalence of GOB(defined by BMI cut-offs recommended by the International Obesity Task Force [11]) increased from $7.35 \%$ (boys) and $2.72 \%$ (girls) in 2010 to $9.33 \%$ (boys) and $3.89 \%$ (girls) in 2014 by 1.98 (boys) and 1.17 (girls) percentage points, while $\mathrm{AOB}$ (defined by waist-to-height ratio $\geq 0.5$ [12]) increased from $15.97 \%$ (boys) and $7.63 \%$ (girls) to $19.73 \%$ (boys) and $10.91 \%$ (girls), by 3.76 (boys) and 3.28 (girls) percentage points (fig. 2). Values of WC and AOB increased faster than BMI and GOB among children and adolescents between 2010 and 2014.

The current International Diabetes Federation definition of metabolic syndrome in pediatrics recommends the use of WC as a mandatory diagnostic component [13]. Evidence suggested that compared to $\mathrm{GOB}, \mathrm{AOB}$ is associated with greater cardiovascular risks [14]. Recently, the use of

\section{KARGER}

E-Mail karger@karger.com

www.karger.com/anm (c) 2016 S. Karger AG, Base

0250-6807/16/0694-0212\$39.50/0
Ying-xiu Zhang

Shandong Center for Disease Control and Prevention Shandong University Institute of Preventive Medicine 16992 Jingshi Road, Jinan, Shandong 250014 (China)

E-Mail sdcdczyx@163.com 
Fig. 1. The increments of BMI and WC Z-score between 2010 and 2014.

Fig. 2. Prevalence of general and abdominal obesity among children and adolescents (2010-2014).

BMI as a cardiovascular risk factor has been questioned and WC received increasing attention in clinical practice. Considering the rapid increase observed in the values of WC and AOB, we suggest that more attention should be paid to the monitoring aspects of $\mathrm{AOB}$ among children and adolescents and that prevention strategies should be more focused on AOB.

\section{References}

1 Wang Y, Lobstein T: Worldwide trends in childhood overweight and obesity. Int J Pediatr Obes 2006;1:11-25.

2 de Onis M, Blössner M, Borghi E: Global prevalence and trends of overweight and obesity among preschool children. Am J Clin Nutr 2010;92:1257-1264.
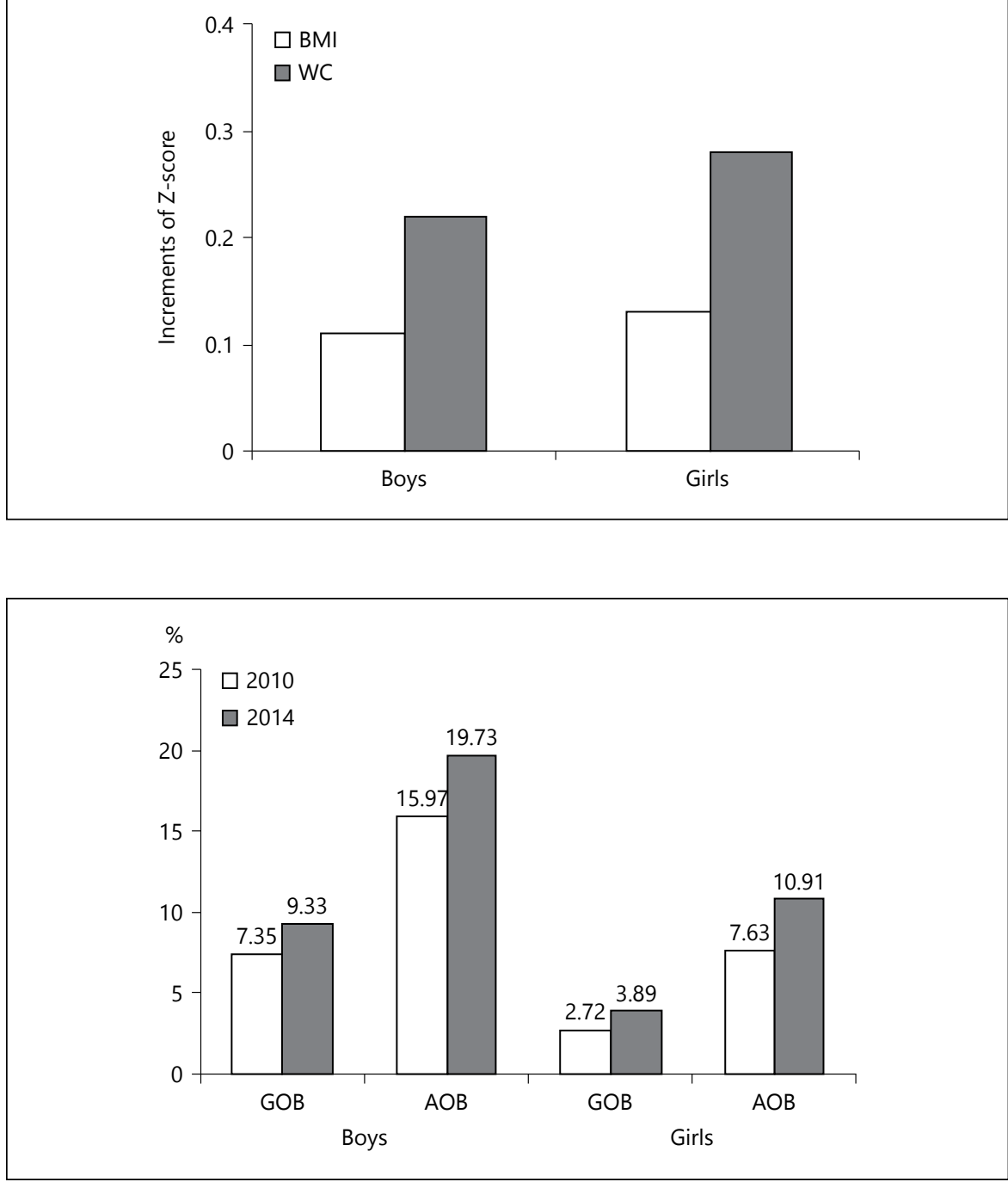

\section{Acknowledgments}

This study was supported by the medical and health program of Shandong, China (2014WS0376). Surveys on students' constitution and health are conducted under the auspices of the department of education in Shandong Province, China. We thank all the team members and all participants. Special thanks to $\mathrm{Mr}$. B. Yu for providing access to the survey data.

\section{Disclosure Statement}

There are no conflicts of interest on behalf of any of the authors.
3 Ogden CL, Carroll MD, Kit BK, Flegal KM: Prevalence of obesity and trends in body mass index among US children and adolescents, 1999-2010. JAMA 2012;307:483-490.

4 Ng M, Fleming T, Robinson M, Thomson B, Graetz N, Margono C, et al: Global, regional, and national prevalence of overweight and obe- sity in children and adults during 1980-2013: a systematic analysis for the Global Burden of Disease Study 2013. Lancet 2014;384:766-781.

5 Franks PW, Hanson RL, Knowler WC, Sievers ML, Bennett PH, Looker HC: Childhood obesity, other cardiovascular risk factors, and premature death. N Engl J Med 2010;362:485-493. 
6 Karnik S, Kanekar A: Childhood obesity: a global public health crisis. Int J Prev Med 2012;3:1-7.

7 Janssen I, Katzmarzyk PT, Ross R: Waist circumference and not body mass index explains obesity-related health risk. Am J Clin Nutr 2004;79:379-384.

8 Mindell JS, Dinsdale H, Ridler C, Rutter HR: Changes in waist circumference among adolescents in England from 1977-1987 to 2005-2007. Public Health 2012;126:695701.
9 Garnett SP, Baur LA, Cowell CT: The prevalence of increased central adiposity in Australian school children 1985 to 2007. Obes Rev 2011:12:887-896.

10 Liang YJ, Xi B, Song AQ, Liu JX, Mi J: Trends in general and abdominal obesity among Chinese children and adolescents 1993-2009. Pediatr Obes 2012;7:355-364.

11 Cole TJ, Lobstein T: Extended international (IOTF) body mass index cut-offs for thinness, overweight and obesity. Pediatr Obes 2012;7: 284-294.
12 McCarthy HD, Ashwell M: A study of central fatness using waist-to-height ratios in UK children and adolescents over two decades supports the simple message - 'keep your waist circumference to less than half your height'. Int J Obes (Lond) 2006;30:988-992.

13 Zimmet P, Alberti G, Kaufman F, Tajima N, Silink M, Arslanian S, et al: The metabolic syndrome in children and adolescents. Lancet 2007;369:2059-2061.

14 Despres JP, Lemieux I: Abdominal obesity and metabolic syndrome. Nature 2006;444: 881-887. 